\title{
RESEARCH ON STATIC PROPERTY OF SUSPEN-DOME STRUCTURE UNDER HEAP LOAD
}

\author{
Jiamin Guo ${ }^{1, *}$, Shilin Dong ${ }^{2}$ and Xingfei Yuan ${ }^{2}$ \\ ${ }^{1}$ College of Ocean Environment and Engineering, Shanghai Maritime University, Shanghai 200135, China \\ ${ }^{2}$ Space Structures Research Center, Zhejiang University, Hangzhou 310027, China \\ *(Corresponding author: E-mail: guojiamin@zju.edu.cn)
}

Received: 24 April 2011; Revised: 2 August 2011; Accepted: 11 August 2011

\begin{abstract}
Suspen-dome includes single-layer latticed shell and the lower cable-struts system, its mechanical properties is better than single-layer latticed shell because of the lower cable-struts system. Heap load might appear during construction or active service, especially during construction. To ensure structure be safe during construction and active service, the structural static property under heap load is chief content in this paper. First, a 1:15 reduced scale suspen-dome model according to the actual structure with $122 \mathrm{~m}$ span is made, which includes single-layer latticed shell, lower cable-struts system and supporting system. Then the measured points for stress and displacement are arranged in model according to experimental contents and model characteristics. And, the structural overall stability under heap load and full-span load are studied and compared. Last, heap load, whose value is $80 \mathrm{Kg}$, are loaded on corresponding model node at 5 different times during experiment in order to study structural static properties under heap load. Results show that the theoretical and experimental data are basically in well agreement, internal forces and displacements is basically linear during loading process, and heap load is more important to structure than full-span load, so it is proposed that heap load should be considered during designing and some measures should be applied to avoid heap load come into being during construction and active service.
\end{abstract}

Keywords: Suspen-dome, Scale model, Similar ratio, Pre-stress, Cable-struts, Heap load

\section{INTRODUCTION}

With the increasing demand for spatial structures, some new types of spatial structures are constantly invented. Until recently, the number of spatial structure type has been thirty eight (Dong [1]). Suspen-dome, which was invented by Kawaguchi in Japan [2], is one of thirty eight types. Suspen-dome including single-layer latticed shell and the lower cable-struts system is a hybrid structure between single-layer latticed shell and cable domes (Geiger [3]). The structural overall stability and stiffness of suspen-dome are better than single-layer latticed shell, and construction difficulty and tension to outer supporting system are lower than cable domes. Until recently, some theoretical and experimental research on this structure have been done in China and other countries $[2,4-12]$. More than ten projects adopted suspen-dome have been designed and constructed based on research achievements. In China, suspen-dome is used as the roof structure in the Tianjin business center hall, in the badminton arena for 2008 Olympic games, in the Changzhou stadium and in the stadium of Jinan Olympic center and so on (Chen et al. [12]). At abroad, similar projects are Guangqiu dome and Juhui dome. Reference (Chen eet al. [8]) study structural static and dynamic properties of the roof structure in the Tianjin business center hall through experiment. Reference (Wang et al. [10]) study mechanical properties of Changzhou stadium by 1:10 scale model. Reference (Zhang et al. [11]) study Jinan Olympic stadium. Those experiments of suspen-dome are good for validating theoretical conclusions, and give us intuitive grasp of structural mechanical properties and construction. During practical construction and usage of spatial structure, heap load is likely to appear because of incorrect construction or active service, especially during construction. Until recently, however, there is less study on mechanical properties of suspen-dome under heap load. From published literatures, only Liu [13] studied the collapse of a hub joint steel shell and pointed out that heap load is main reason which causes structure to collapse. Because heap load possibly has adverse effect on structural mechanical properties. At the 
same time, to instruct practical construction and usage correctly, knowing more knowledge about mechanical properties of suspen-dome under heap load is chief content in the paper. First, a 1:15 reduced scale suspen-dome model according to the actual structure with 122 meters span is made and shown in Figure 1-2. The model structural span is 8 meters, and its rise is 0.8 meters, which includes single-layer latticed shell, lower cable-struts system and supporting system. Structural static property under heap load are studied through structural model. Experimental and theoretical results in the paper can be referred by similar practical structure.

\section{DESIGN AND CONSTRUCTION OF EXPERIMENTAL MODEL}

Suspen-dome model is composed of single-layer latticed shell, cable-struts system and supporting system. Cable-struts system includes radial cables, hoop cables and struts. Its composition can be seen in Figure 1. After considering some practical factors, for example, experimental equipments which can be utilized, the area of experimental field and the experimental cost and so on (Fu [14]), the practical structure with 122 meters span is scaled to the model with 8 meters span. Thus, its geometrical similar ratio is equal to about 1:15. The structure model is shown in Figure 2.
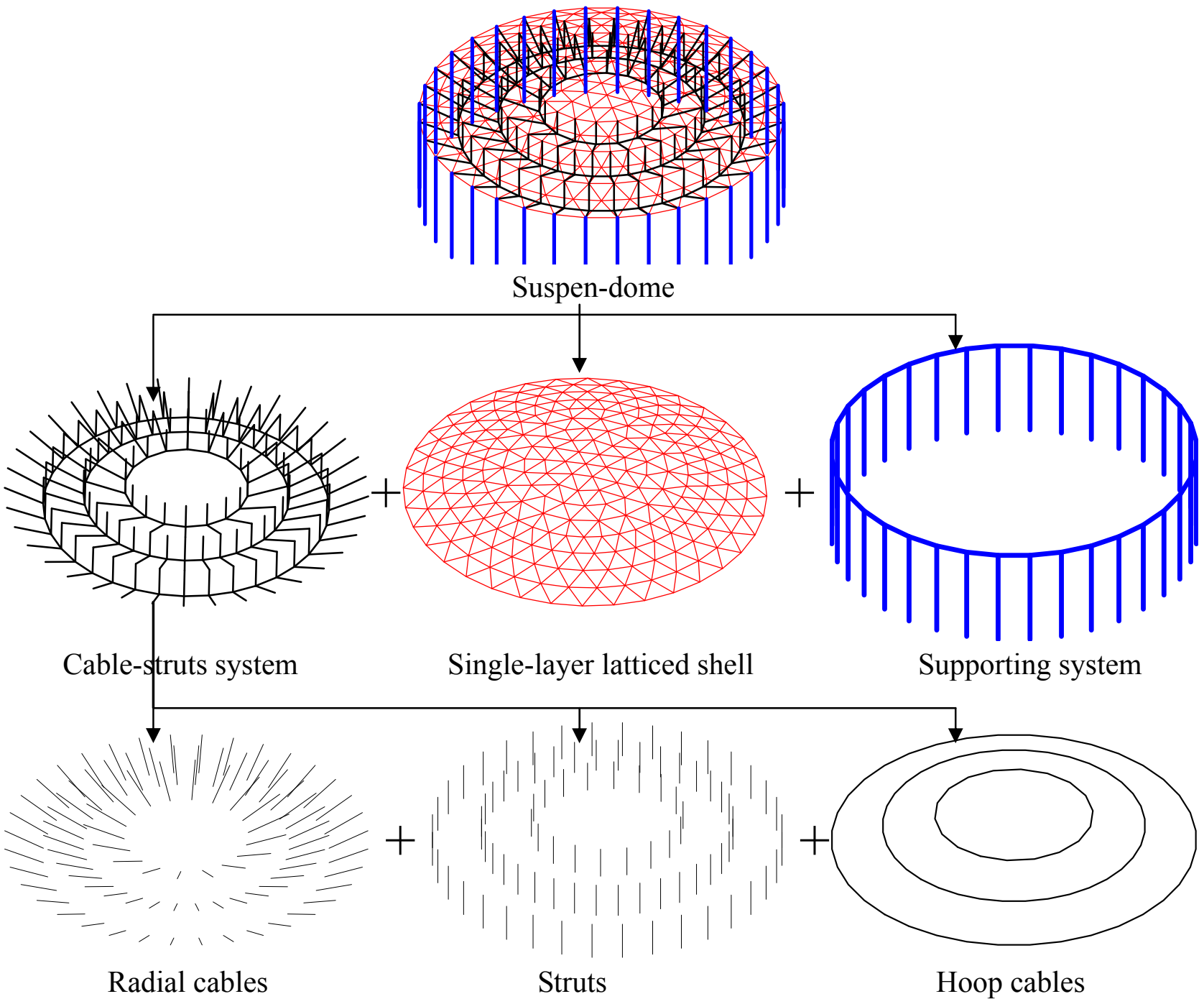

Figure 1. Composition of Suspen-dome 


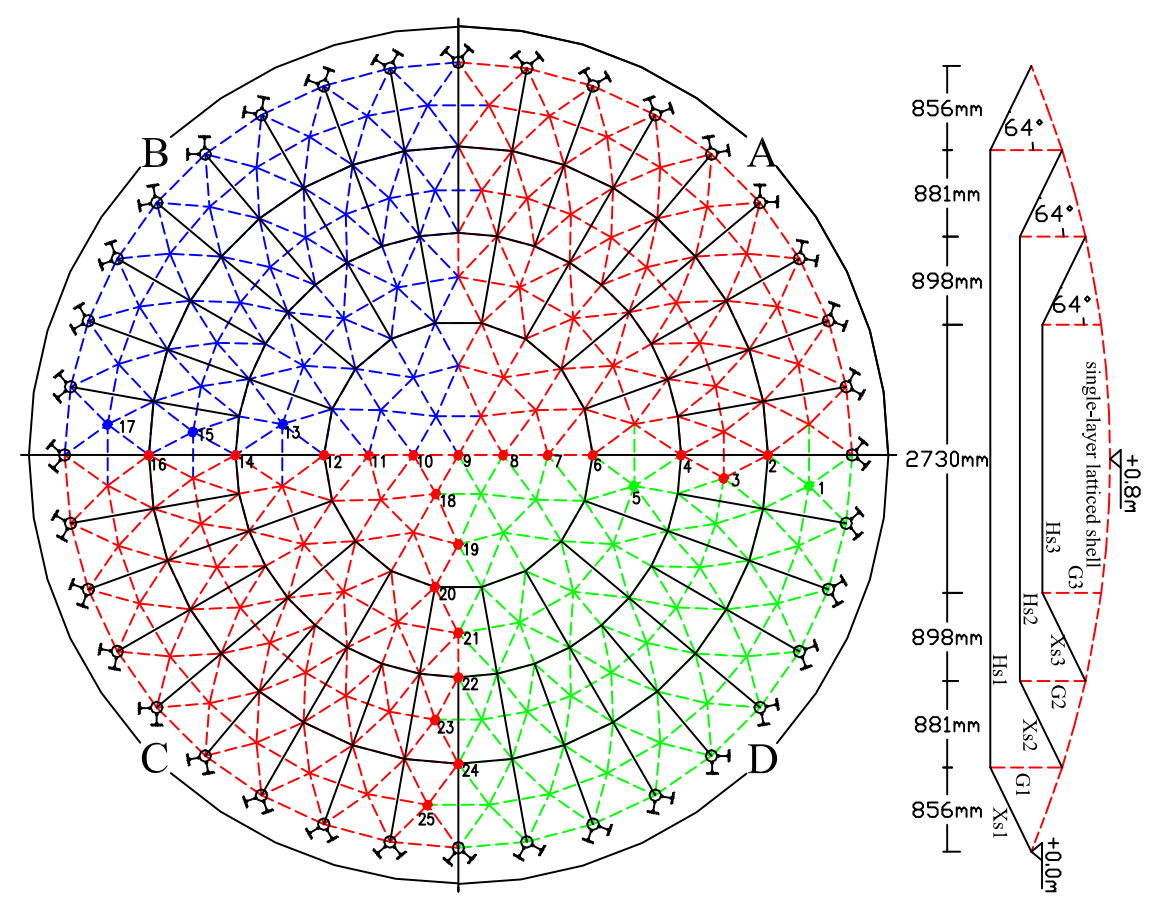

(a) Calculation Model of Suspen-dome

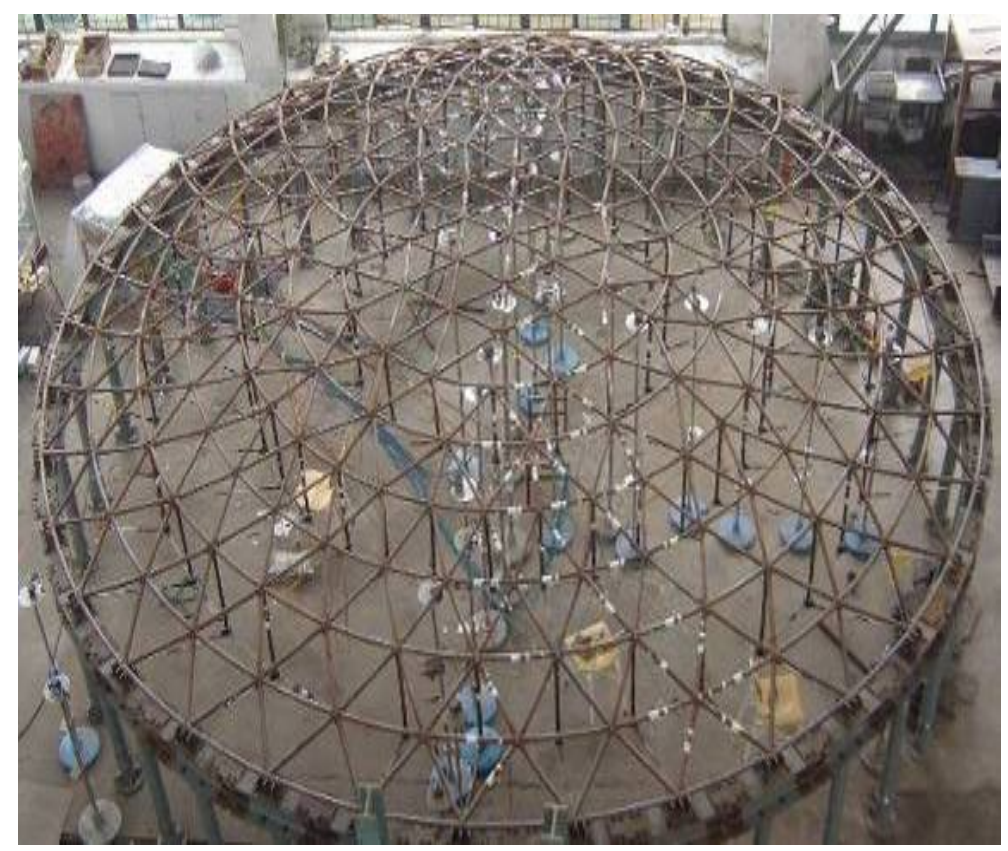

(b) Experimental Model of Suspen-dome

Figure 2. Model of Suspen-dome

\subsection{Design of Supporting System}

From Figure 1-2 we can see that suspen-dome is supported on supporting system. Diameter of supporting system is equal to diameter of upper single-layer latticed shell, whose value is 8 meters. Supporting system is composed of thirty six basic elements which are easy to manufacture, to move and to connect. Basic element, which includes ring beams and pillars, can be reused. Ring beam is welding I-beam, pillar is steel tube whose type is $\Phi 114 \times 6$. Ring beam is connected with plate, which lays on the top of pillar, by four $\Phi 16$ high-strength bolts. There is a circle plate, whose diameter and thickness is respectively $240 \mathrm{~mm}$ and $20 \mathrm{~mm}$, on the bottom of pillar. Because floor is 
at different levels, a tunable socket is utilized in pillars in order to avoid pillars suspend. In order to strength ring beam stiffness of supporting system, one welding I-beam connects with another by steel plate in top and seat flange and by steel plate in inner and outer web. Connection of basic elements is shown in Figure 3.

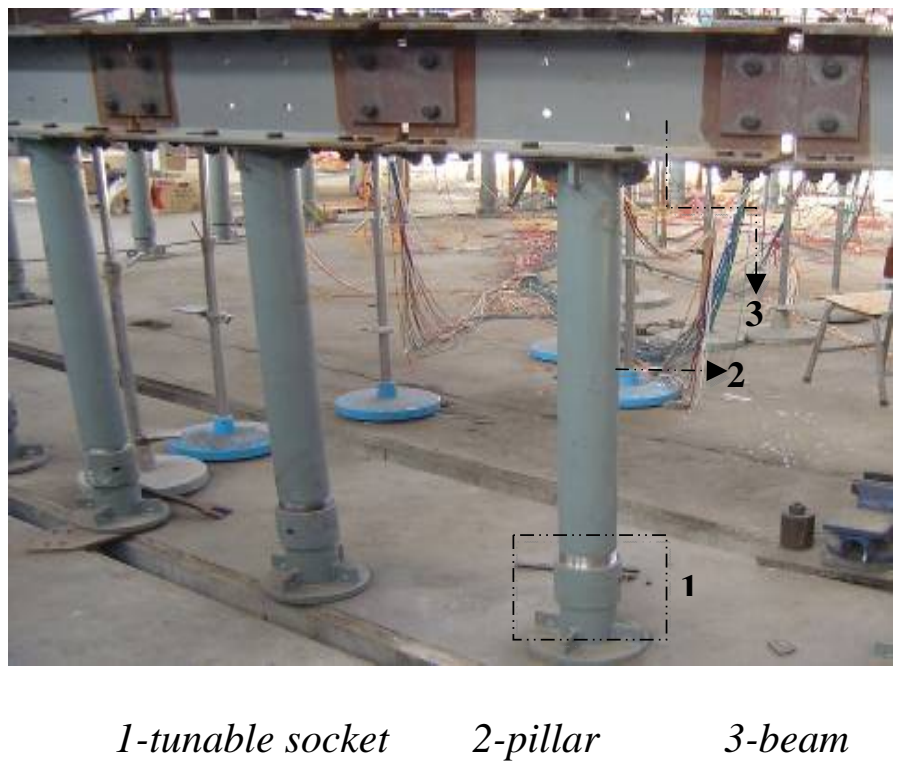

Figure 3. Connection of Basic Elements

\subsection{Design of Single-Layer Latticed Shell}

Geometrical similar ratio, which can be denoted as $c_{l}$, is $1: 15$, nodal coordinate and fabrication length of elements are calculated according to the above similar ratio and practical structural drawings. So model span is set as 8 meters and its rise is 0.8 meters. When the mid-span node in single-layer latticed shell is selected as reference origin of coordinates, the model nodal coordinates scaled by $c_{l}$ are shown in Figure 4 . Elements in single-layer latticed shell are entirely objected to axial force[15], so the paper scales the model bar section according to axial stress consistent principle. Load similar ratio $\left(C_{q}\right)$ is determined by experimental loading equipments, loading way and loading value and so on. After considering above influence factors, the value of $c_{q}$ is set as 2 during design experiment model. The relation among geometrical similar ratio, load similar ratio and structural sectional similar ratio can be summarized as the following Eq. 1. Structural sectional similar ratio $\left(c_{A}\right)$ can be calculated by the following equation (1). When $c_{l}$ is $1: 15, c_{q}$ is equal to 2 , structural sectional similar ratio $\left(c_{A}\right)$ is 0.0086 .

$c_{A}=\left(c_{l}\right)^{2} \cdot c_{q}$

First, practical section area is theoretically scaled to model section by the structural sectional similar ratio described above. Then, production type of market supply, purchase cycle of production, manufacture craft and influence of element section area on structural mechanical property [15] are considered. Last, sectional area in single-layer latticed shell is shown in Figure 5, where 1 stands for $\Phi 30 \times 1.5$ and 2 stands for $\Phi 35 \times 1.5$. Model sectional types selected are shown in table 1 . 


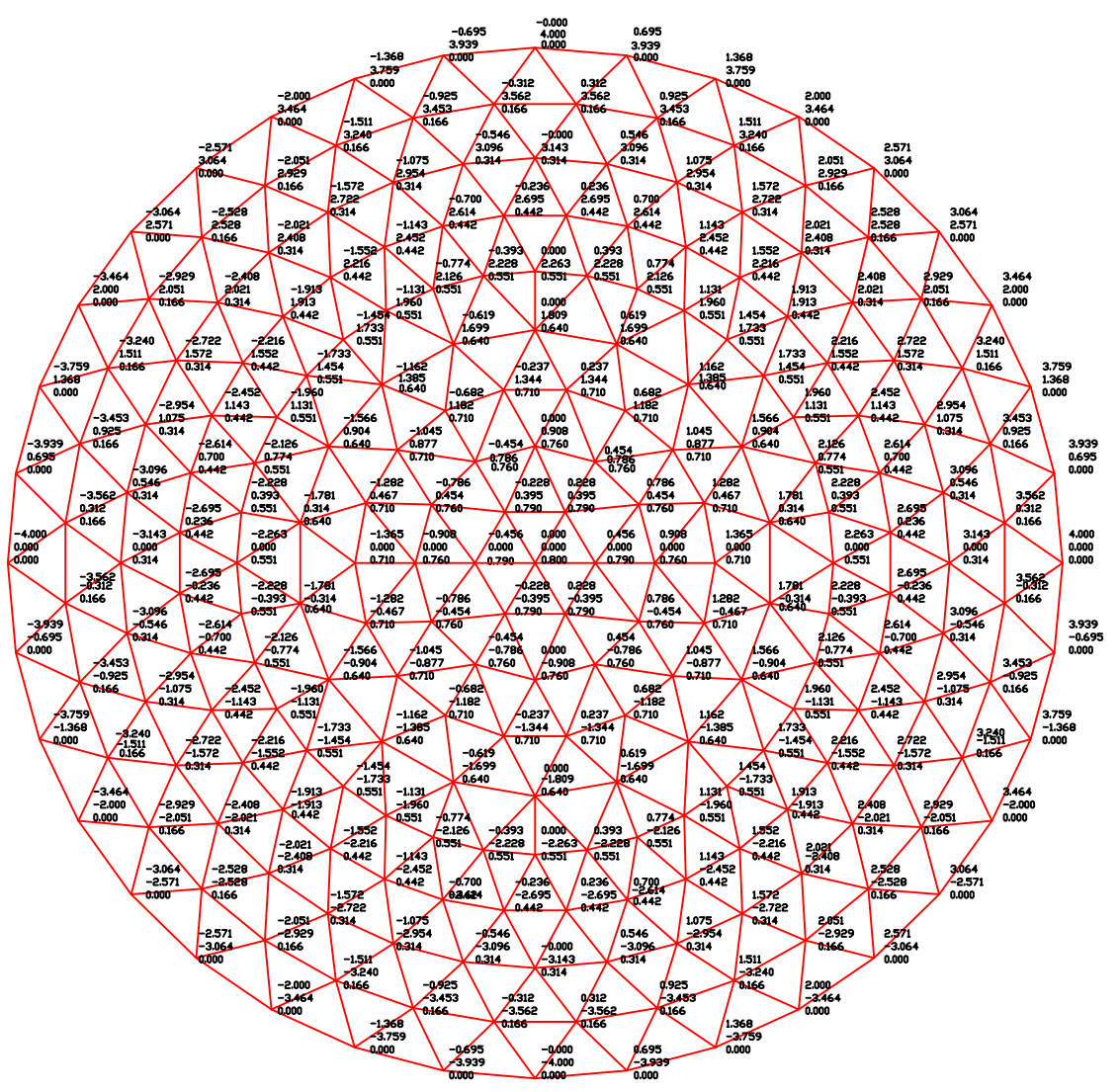

Figure 4. Nodal Coordinates of Single-layer Latticed Shell

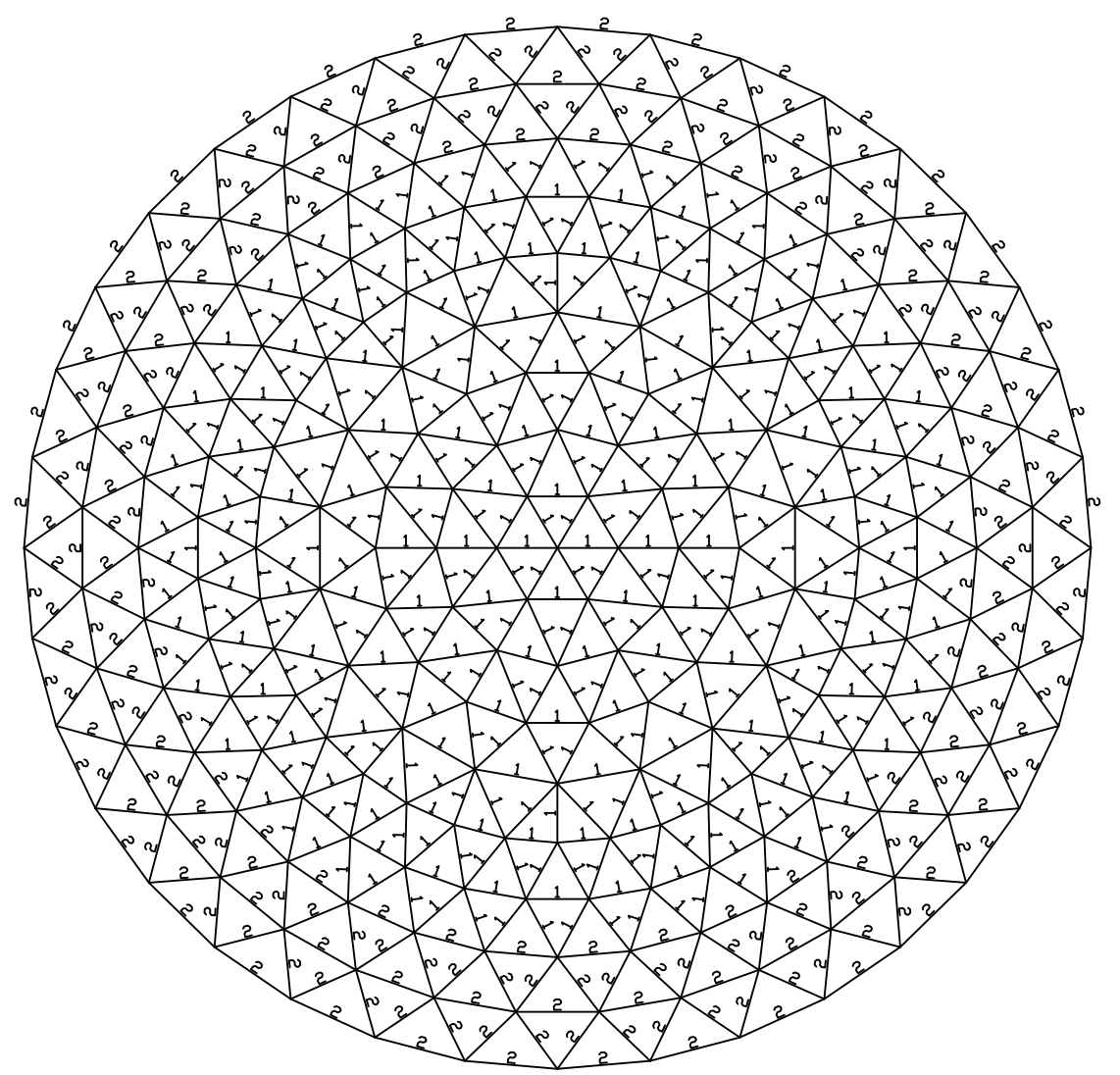

Figure 5. Distribution of Sectional Type in Single-layer Latticed Shell 
Table 1. Sectional Type of Practical Structure and Model Structure

\begin{tabular}{ccc||ccc}
\hline Member & Practical structure & Model structure & Member & Practical structure & Model structure \\
\hline Xs1 & $\Phi 85$ & $\Phi 8$ & 1 & $\Phi 377 \times 14$ & $\Phi 30 \times 1.5$ \\
Xs2 & $\Phi 55$ & $\Phi 5$ & & & \\
Xs3 & $\Phi 45$ & $\Phi 5$ & 2 & & \\
Hs1 & $2 \Phi 5 \times 199$ & $2 \Phi 8$ & G1 & $\Phi 299 \times 10$ & $\Phi 30 \times 16$ \\
Hs2 & $\Phi 5 \times 165$ & $\Phi 8$ & G2 & $\Phi 245 \times 6.5$ & $\Phi 30 \times 1.5$ \\
Hs3 & $\Phi 5 \times 55$ & $\Phi 6$ & G3 & $\Phi 219 \times 6$ & $\Phi 30 \times 1.5$ \\
\hline
\end{tabular}

\subsection{Design of Cable-Struts System}

Cable-struts system of structure model includes 90 radial cables, 90 struts and 12 hoop cables. Though hoop cable is theoretically continuous, for easy of manufacture and tension, each hoop cable is divided into four parts, total number of hoop cable is 12 parts. Struts, radial cables and hoop cables are shown in Figure 6. From Figure 6, we can see the length of each element can be controlled by a tunable socket. Hoop cables are made of $\Phi 8$ and $\Phi 6$ type wire rope, the effective sectional area and elasticity modulus of wire rope are respectively unknown to us, the product of effective sectional area and elasticity modulus, however, can be checked by electronic tensile tester, so the product of effective sectional area and elasticity modulus is used for sectional rigid during calculation. The sectional rigid of $\Phi 8$ and $\Phi 6$ type wire rope from checking are $2213095 \mathrm{~N}$ and $1311274 \mathrm{~N}$, respectively. Radial cables are made of stainless steel bars, struts are made of circle steel tube. Tunable socket in struts, radial cables and hoop cables can be turned to add pre-stress to overall structure. A standard measured part, on which strain gauges can be arranged, is installed in radial cables and hoop cables. The sectional type of cable-struts can also be seen in Table 1 .

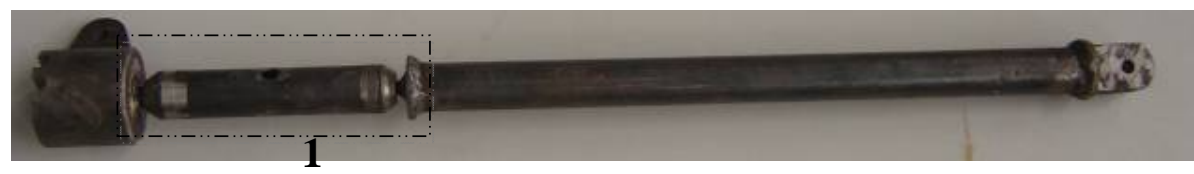

(a) Struts

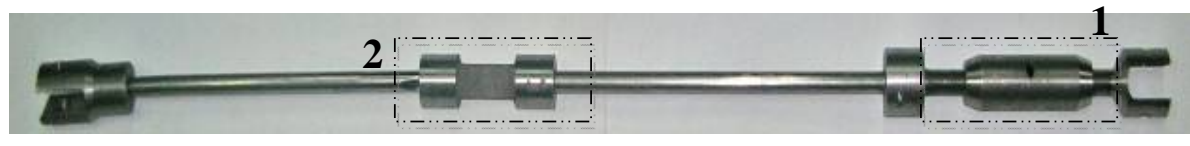

(b) Radial cables

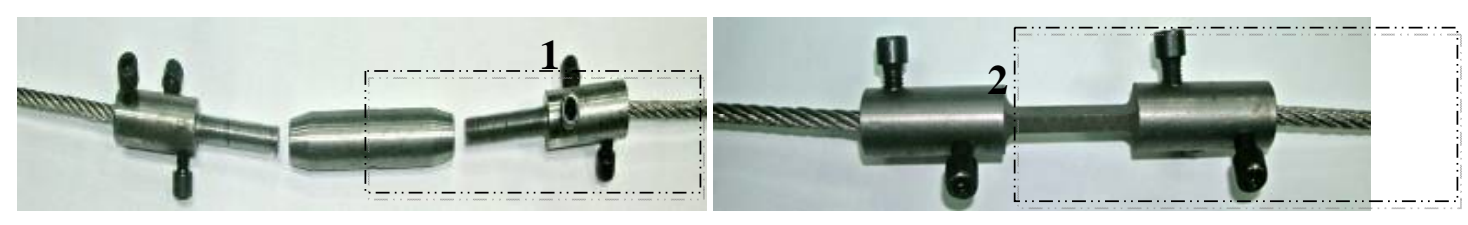

(c) Hoop cables

1-tunable socket

2-standard measured part

Figure 6. Cable-struts 


\subsection{Design of Nodes}

There are 3 types of nodes in model structure. They are upper single-layer latticed shell node, supporting node and cable-struts node. The principle instructing node design is easy to manufacture on the based that the structure is safe. Nodes in single-layer latticed shell adopts tubular joint with simple strength plate, which is simpler than practical node, node in mid-span of single-layer latticed shell is shown in Figure 7. Supporting node, which is shown in Figure 8, is also simpler than practical node. Supporting node connects with elements in single-layer latticed shell by welding. The lower cable-struts node, through which a continuous hoop cable goes, is shown in Figure 9. The node connected by radial cables, struts and hoop cables is shown in Figure 10.

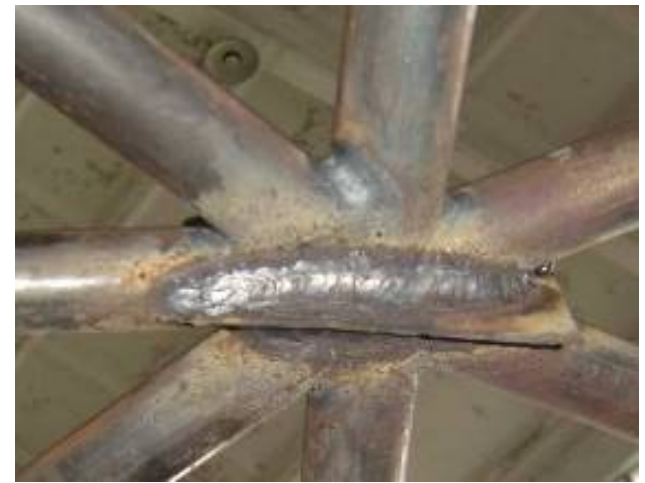

Figure 7. Node in Single-layer Latticed Shell

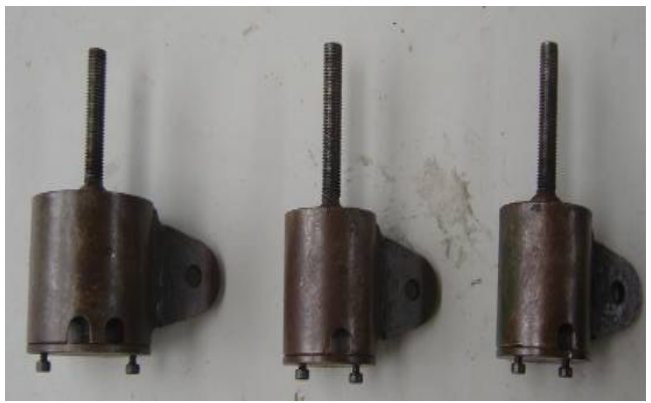

Figure 9. Node of Struts

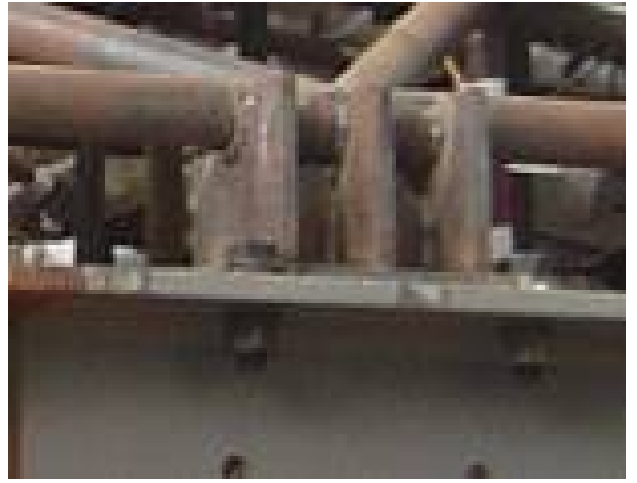

Figure 8. Supporting Node

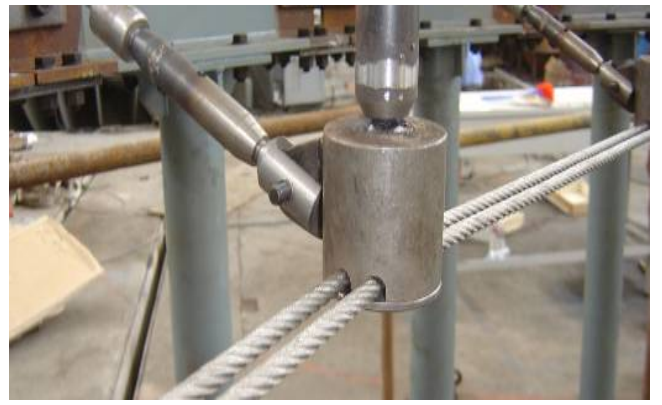

Figure 10. Node Connection

\section{ARRANGEMENT OF EXPERIMENTAL MEASURED POINTS}

During experiment, some element inner force and nodal displacement will be measured in order to estimate structural mechanical properties under heap load. Inner force of structural elements are measured by $\mathrm{DH} 3815 \mathrm{~N}$ type static resistance strain measurers, the type of strain gage used during experiment is $3 X 5 \mathrm{~mm}$. Structural nodal displacement are measured by dial indicator. To avoid eccentricity of element cause measure errors, two strain gages are arranged in middle of elements, and they are symmetry and parallel to element axial line, two strain gages are in series.

After considering some factors which include measurement content, measurement equipment and structural symmetry and so on, 90 strain points are selected in single-layer latticed shell. For easy of tension control, cables and struts laid in a quarter area of the lower cable-struts system are all arranged by measured points, one third of cables and struts laid in other 3 quarter area of bottom cable-struts system are arranged by measured points. The total number of measured points for strain selected in cable-struts system is 102, 12 measured points lay in hoop cables, 45 measured points lay in radial cables, 45 measured points lay in struts. The number of measured points for displacement is 25 , in which 17 dial indicators lay in the same line, other 8 dial indicators lay in 
another line, which is right to above line. All strain measured points are shown in Figure 11 and displacement measured points are shown in Figure 2.

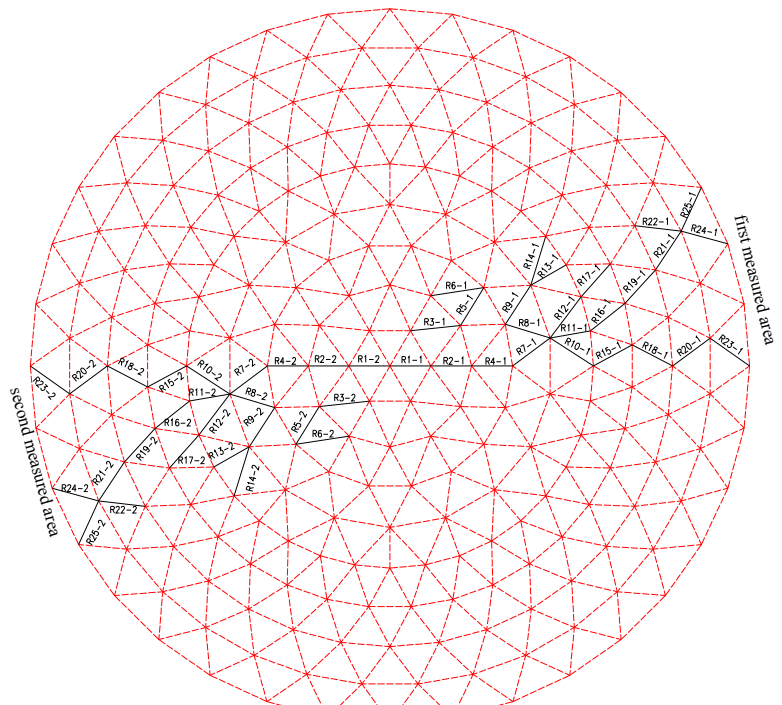

(a)Radial elements

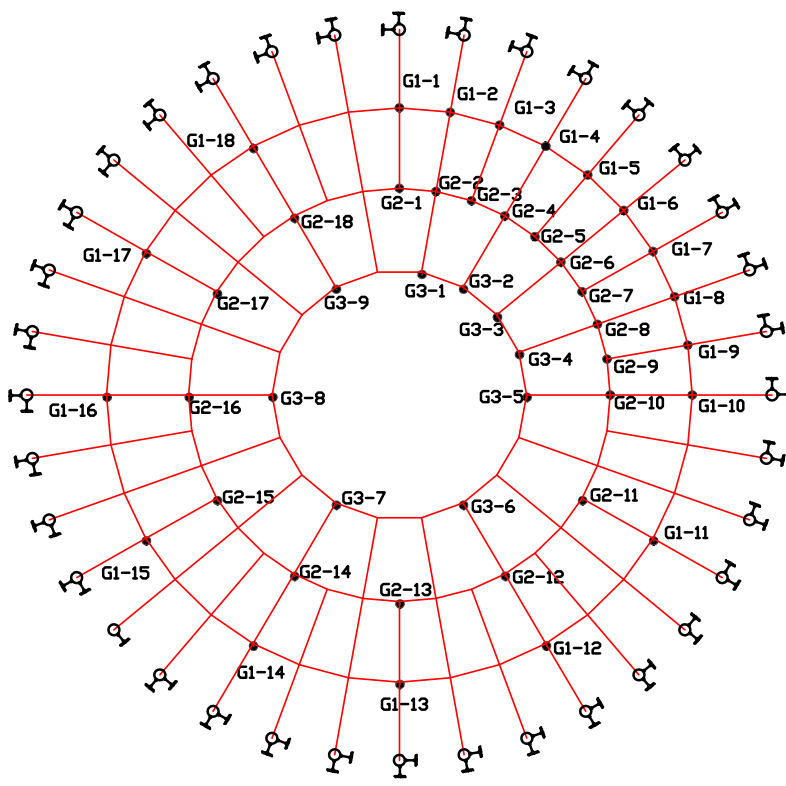

(c) Struts

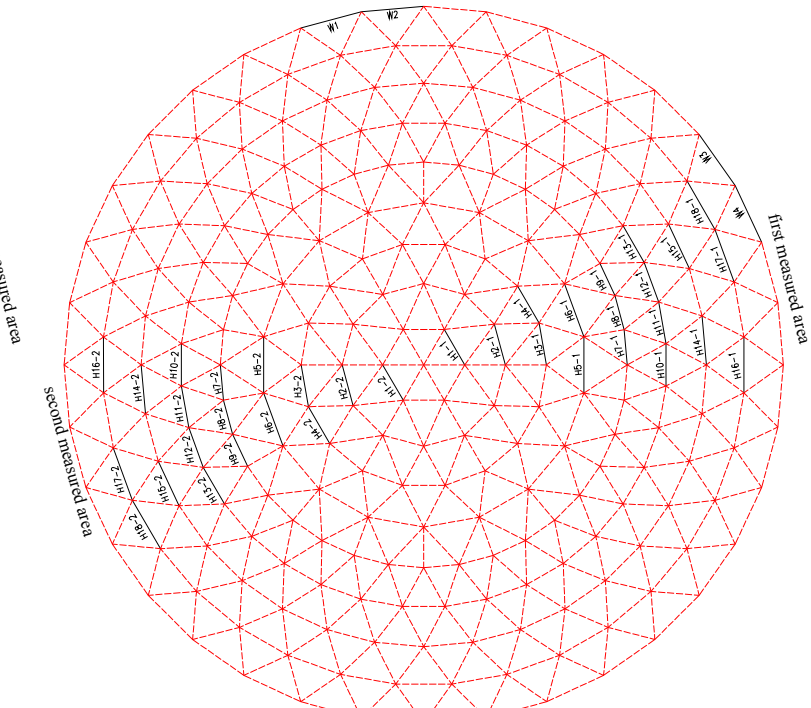

(b) Hoop elements

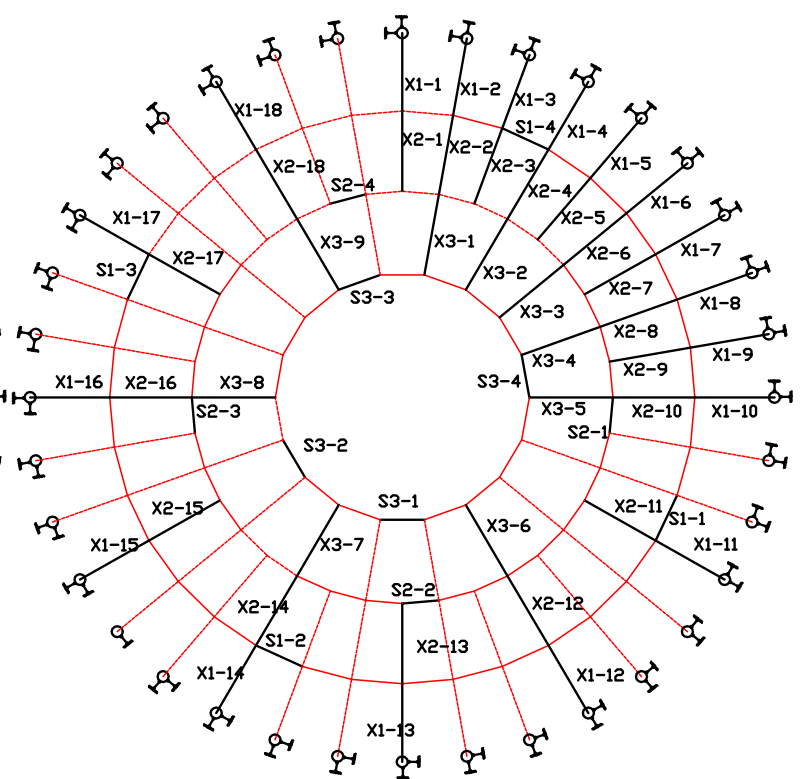

(d) Hoop cable elements and radial cable elements

Figure 11. Arrangement Plan for Stress Measured Points

\section{THEORETICAL AND EXPERIMENTAL RESEARCH ON MODEL STRUCTURE}

During practical construction and active service of spatial structure, heap load is likely to appear because of incorrect construction or usage, especially during construction. Structural static properties under heap load will be theoretically and experimentally studied in the following text. The total node number in single-layer latticed shell is 235, among which 199 nodes are not supporting node, among which 90 nodes lay on the top of struts. During experiment some sandbags are put on corresponding points to simulate load in structure. During loading sandbags, frame is constructed above suspen-dome model to ensure load safely and conveniently. Heap load is simulated by loading some sandbags on " $\mathrm{A}$ " area (which is just in 1st measured area), which is a quarter of single-layer latticed shell as shown in Figure 2. To be convenient, all sandbags which are 
loaded each point are $80 \mathrm{~kg}$. In the process of loading, $80 \mathrm{~kg}$ loads are loaded corresponding points at 5 different times, load magnitude is $20 \mathrm{~kg}, 20 \mathrm{~kg}, 20 \mathrm{~kg}, 10 \mathrm{~kg}, 10 \mathrm{~kg}$, respectively. Measured data can be read after ten to fifteen minutes from completing load each time in order to ensure structural response to outer loads complete. The pre-stress value in model structure is determined by practical structural pre-stress value according to axial stress consistent principle. The pre-stress value in hoop cables, which have been tensioned before loading, is shown in table 2 .

Table 2. Pre-stress Value of Hoop Cables before Loading

\begin{tabular}{c||c||c}
\hline $\mathrm{Hs} 1 / \mathrm{kN}$ & $\mathrm{Hs} 2 / \mathrm{kN}$ & $\mathrm{Hs} 3 / \mathrm{kN}$ \\
\hline 22.7 & 11.8 & 4.14 \\
\hline
\end{tabular}

To ensure model structure be safe during loading and to know the difference of mechanical properties between under full-span load (loading on A, B, C and D area, which is shown in Figure 2) and heap load, the overall stability of structure model under full-span load and heap load, whose basic magnitude in each corresponding node is $80 \mathrm{Kg}$, are first calculated by finite element software ANSYS[16]. The curves between nodal vertical displacement and loads, which can reflect structural overall stability, are drawn in Figure 12(a). When heap load reaches critical value, the stress distribution of single-layer latticed shell is given in Figure 12(b). Because the critical load value under heap load is smaller than full-span load, in order to compare conveniently, the stress distribution, which can be seen in Figure 12(c), under full-span load is given when full-span load factor reaches heap critical value.

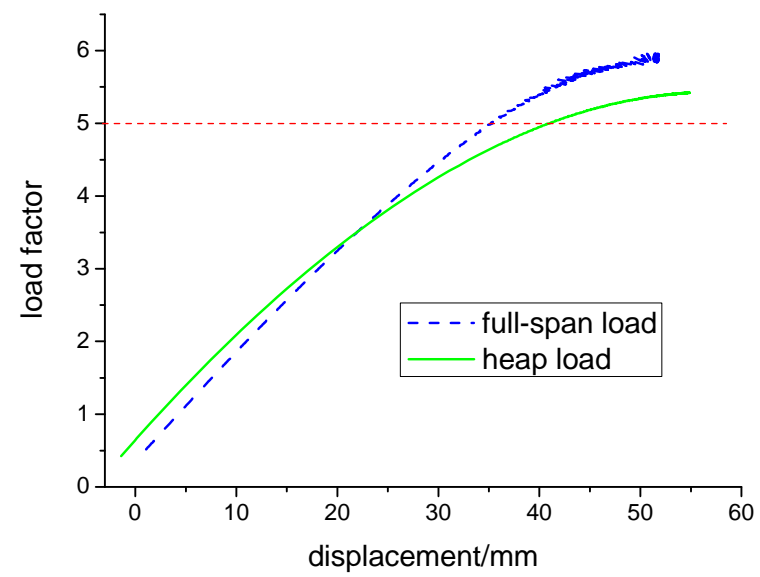

(a) Load-displacement curves

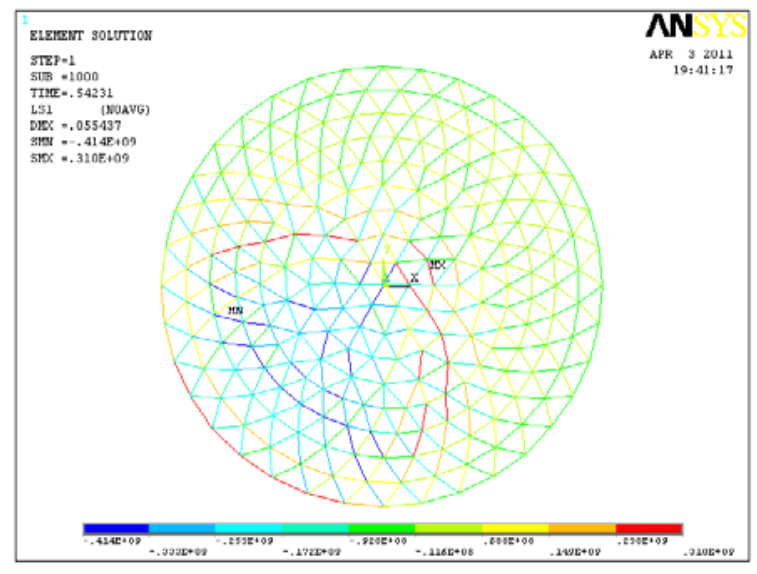

(b) Stress distribution under heap critical load

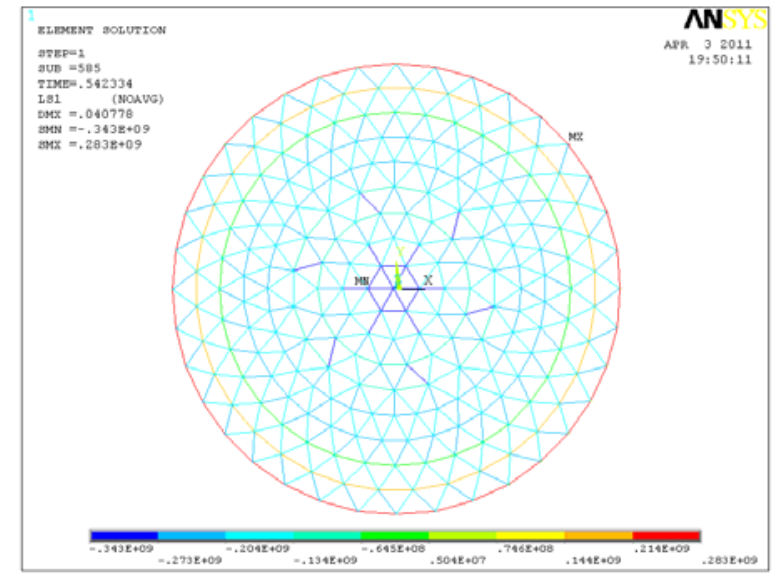

(c) Stress distribution under full-span load 
From Figure 12, we can see the overall stability factor are more than 5 under full-span load and heap load. So the structure is impossible to loss its overall stability during the imposing of heap load. We can also see that the overall stability factor and structural stiffness under full-span load is better than under heap load. From Figure 12(b)-(c), we can also see that the stress magnitude of single-layer latticed shell under critical heap load is more than corresponding full-span load. Calculation results show that the structural stability property under heap load is little worse than full-span load. From Figure 12(a), we can see that two curves do not intersect in origin of coordinates because of influence of pre-stress on structural displacement.

In order to know much more about mechanical properties under heap load, heap load are loaded in structure during experiment. Inner force of elements and nodal displacement are recorded in the process of loading. The process of loading is shown in Figure 13. Because measured data are so much that they can't be all listed in the paper, only some measured points are concerned, theoretical and experimental results during loading are listed in table 3 and table 4. Because sectional area of struts are big during design, strain measured in struts are small, they are almost less than $30 \mu \varepsilon$, but the errors from type static resistance strain measurers fall within $+/-3$, and there are also some errors between theoretical model and experimental model after the structure is tensioned, so there are much errors between theoretical model and experimental model in struts during loading. Here, those data of struts are not listed in the paper.

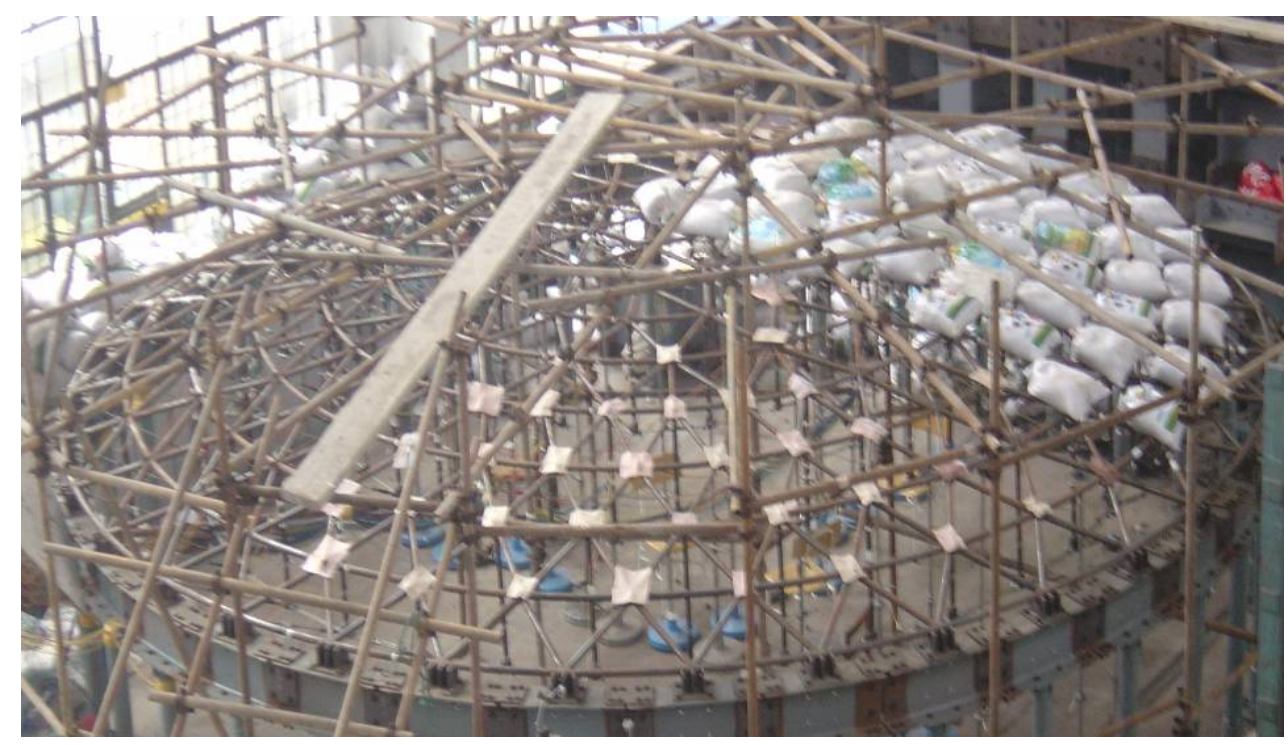

Figure 13. Loading of Heap Load

Table 3. Theoretical and Measured Axial Force of Partial Cable-struts during Loading (units: N)

\begin{tabular}{cccccccc}
\hline load & Inner force & \multicolumn{7}{c}{ Measured points number } \\
\cline { 3 - 8 } process & $/ \mathrm{N}$ & $\mathrm{X} 1-7$ & $\mathrm{X} 2-8$ & $\mathrm{X} 3-5$ & $\mathrm{~S} 1-2$ & $\mathrm{~S} 2-2$ & $\mathrm{~S} 3-2$ \\
\hline \multirow{3}{*}{ 1st } & Theoretical & 4359.5 & 2268.9 & 1541.8 & 22658.8 & 11767.4 & 4002.1 \\
& measured & 4301.3 & 2249.5 & 1549.1 & 21877.2 & 11601.9 & 3811.0 \\
& Relative error & -1.3 & -0.9 & 0.5 & -3.4 & -1.4 & -4.8 \\
\hline \hline \multirow{3}{*}{ 2nd } & Theoretical & 4403.9 & 2283.0 & 1539.4 & 22895.3 & 11840.4 & 3996.0 \\
& measured & 4326.0 & 2249.5 & 1549.1 & 22289.2 & 11733.8 & 3811.0 \\
& Relative error & -1.8 & -1.5 & 0.6 & -2.6 & -0.9 & -4.6 \\
\hline \hline \multirow{3}{*}{$3 \mathrm{rd}$} & Theoretical & 4448.9 & 2297.4 & 1536.8 & 23135.0 & 11915.0 & 3989.1 \\
& measured & 4412.5 & 2274.2 & 1557.4 & 22701.2 & 11915.0 & 3841.9 \\
& Relative error & -0.8 & -1.0 & 1.3 & -1.9 & 0.0 & -3.7 \\
\hline \hline
\end{tabular}




\begin{tabular}{|c|c|c|c|c|c|c|c|}
\hline \multirow{3}{*}{4 th } & Theoretical & 4494.6 & 2312.1 & 1533.6 & 23377.7 & 11991.7 & 3981.2 \\
\hline & measured & 4474.3 & 2315.4 & 1565.6 & 23113.2 & 12046.9 & 3903.7 \\
\hline & Relative error & -0.5 & 0.1 & 2.1 & -1.1 & 0.5 & -1.9 \\
\hline \multirow{3}{*}{5 th } & Theoretical & $4+4517.6$ & 2319.7 & 1532.0 & 23500.9 & 12030.7 & 3976.8 \\
\hline & measured & 4499.0 & 2331.9 & 1573.8 & 23278.0 & 12129.3 & 3924.3 \\
\hline & Relative error & -0.4 & 0.5 & 2.7 & -0.9 & 0.8 & -1.3 \\
\hline \multirow{2}{*}{$\begin{array}{c}\text { load } \\
\text { process }\end{array}$} & Inner force & \multicolumn{6}{|c|}{ Measured points number } \\
\hline & $/ \mathrm{N}$ & $\mathrm{X} 1-13$ & $\mathrm{X} 2-13$ & X3-9 & $\mathrm{S} 1-4$ & S2-3 & S3-3 \\
\hline \multirow{3}{*}{$1 \mathrm{st}$} & Theoretical & 4362.1 & 2264.6 & 1542.1 & 22658.8 & 11767.4 & 4002.1 \\
\hline & measured & 4214.8 & 2216.6 & 1549.1 & 22660.0 & 11387.7 & 3975.8 \\
\hline & Relative error & -3.4 & -2.1 & 0.5 & 0.0 & -3.2 & -0.7 \\
\hline \multirow{3}{*}{ 2nd } & Theoretical & 4409.4 & 2278.3 & 1539.3 & 22888.2 & 11840.7 & 3996.3 \\
\hline & measured & 4301.3 & 2224.8 & 1549.1 & 23072.0 & 11503.0 & 3975.8 \\
\hline & Relative error & -2.5 & -2.3 & 0.6 & 0.8 & -2.9 & -0.5 \\
\hline \multirow{3}{*}{$3 \mathrm{rd}$} & Theoretical & 44457.4 & 2292.3 & 1536.2 & 23120.6 & 11915.7 & 3989.5 \\
\hline & measured & 4375.4 & 2233.0 & 1557.4 & 23525.2 & 11684.3 & 4047.9 \\
\hline & Relative error & -1.8 & -2.6 & 1.4 & 1.7 & -1.9 & 1.5 \\
\hline \multirow{3}{*}{4 th } & Theoretical & 4505.8 & 2306.8 & 1532.6 & 23356.3 & 11992.7 & 3981.8 \\
\hline & measured & 4462.0 & 2274.2 & 1565.6 & 23937.2 & 11799.7 & 4078.8 \\
\hline & Relative error & -1.0 & -1.4 & 2.2 & 2.5 & -1.6 & 2.4 \\
\hline \multirow{3}{*}{5 th } & Theoretical & 4530.4 & 2314.2 & 1530.7 & 23475.3 & 12031.7 & 3977.6 \\
\hline & measured & 4499.0 & 2282.5 & 1606.8 & 24143.2 & 11915.0 & 4089.1 \\
\hline & Relative error & -0.7 & -1.4 & 5.0 & 2.8 & -1.0 & 2.8 \\
\hline
\end{tabular}

Table 4. Theoretical and Measured Displacement of Partial Node during Loading

\begin{tabular}{ccccccccc}
\hline \multirow{2}{*}{$\begin{array}{c}\text { load } \\
\text { process }\end{array}$} & displacement & \multicolumn{7}{c}{ dial indicators number } \\
\cline { 3 - 9 } 1st & $/ \mathrm{mm}$ & 1 & 2 & 3 & 5 & 6 & 8 & 9 \\
& Theoretical & 0.04 & 0.07 & 0.09 & 0.10 & 0.10 & -0.22 & -0.72 \\
& measured & -0.04 & 0.07 & 0.11 & 0.24 & 0.25 & -0.35 & -0.94 \\
& Absolute error & 0.08 & 0.00 & -0.02 & -0.14 & -0.15 & 0.13 & 0.22 \\
\hline \multirow{3}{*}{ 2nd } & Theoretical & 0.08 & 0.14 & 0.18 & 0.21 & 0.20 & -0.43 & -1.45 \\
& measured & -0.04 & 0.10 & 0.18 & 0.47 & 0.50 & -0.68 & -1.88 \\
& Absolute error & 0.12 & 0.04 & 0.00 & -0.26 & -0.30 & 0.25 & 0.43 \\
\hline \multirow{3}{*}{ 3rd } & Theoretical & 0.13 & 0.22 & 0.27 & 0.32 & 0.31 & -0.63 & -2.19 \\
& measured & -0.02 & 0.15 & 0.26 & 0.62 & 0.78 & -0.96 & -2.87 \\
& Absolute error & 0.15 & 0.07 & 0.01 & -0.30 & -0.47 & 0.33 & 0.68 \\
\hline \multirow{3}{*}{ 4th } & Theoretical & 0.15 & 0.25 & 0.31 & 0.37 & 0.37 & -0.73 & -2.55 \\
& measured & -0.01 & 0.17 & 0.29 & 0.73 & 0.91 & -1.15 & -3.35 \\
& Absolute error & 0.16 & 0.08 & 0.02 & -0.36 & -0.54 & 0.42 & 0.80 \\
\hline \multirow{3}{*}{ 5th } & Theoretical & 0.17 & 0.29 & 0.36 & 0.41 & 0.38 & -0.68 & -2.50 \\
& measured & 0.00 & 0.20 & 0.31 & 0.94 & 1.03 & -1.17 & -3.66 \\
& Absolute error & 0.17 & 0.09 & 0.05 & -0.53 & -0.65 & 0.49 & 1.16 \\
\hline
\end{tabular}


The Table 3 and Table 4 show that the theoretical and experimental data are basically in well agreement. The most error appears in measured point whose number is X3-9, the error value is five percent after fifth loads is loaded. The errors in displacement lay between $-1 \mathrm{~mm}$ and $+1 \mathrm{~mm}$, the displacement values listed in the paper are all small, less than $10 \mathrm{~mm}$. In order to further analysis mechanical properties under heap load in detail, comparison between the theoretical and experimental data for some inner force, nodal displacement in single-layer latticed shell during loading are given in Figure 14. After all nodal loads are loaded on corresponding node, theoretical and experimental distribution of stress and displacement in single-layer latticed shell under heap load, theoretical stress distribution under full-span load and the comparison among them are given in Figure 15.

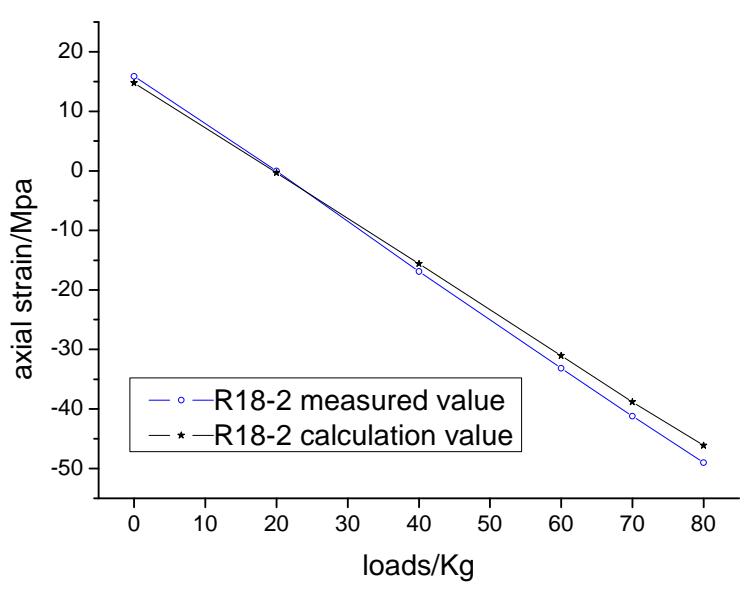

(a) R18-2

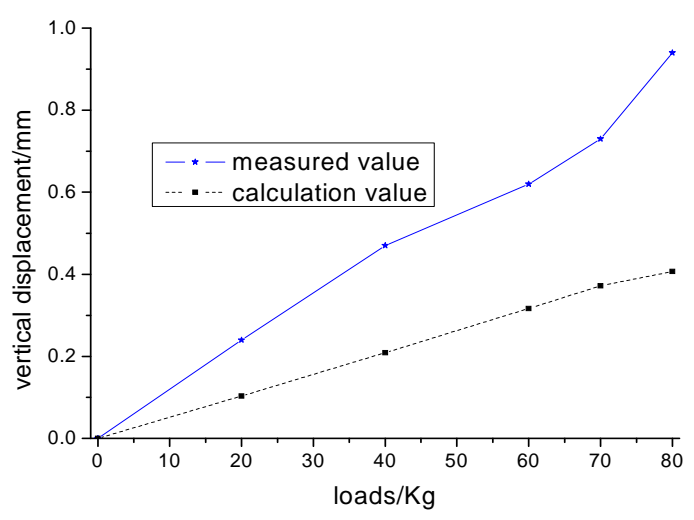

(c) 5th dial indicator

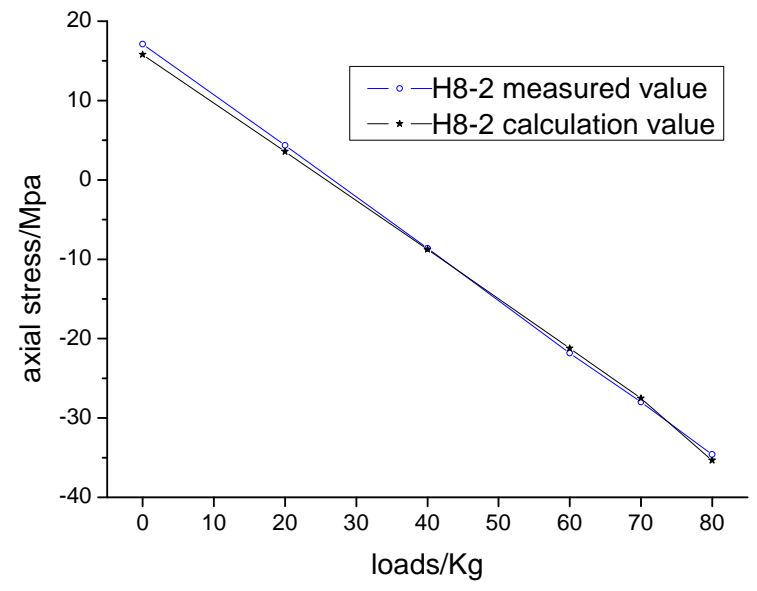

(b) $\mathrm{H} 8-2$

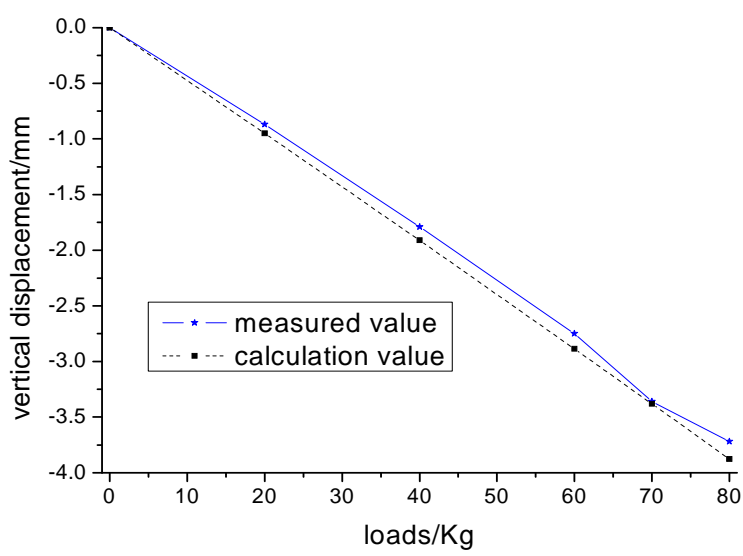

(d) 14th dial indicator

Figure 14. Comparison of Measured and Calculation Results during Loading

From Figure 14(a)-(b), we can see that the theoretical and experimental stress results are basically in well agreement. From Figure 14(c)-(d), we can see that the theoretical and experimental displacement in 14th dial indicator is basely available, while there is obvious difference between theory and experiment in 5th dial indicator. At the same time, we can also see that the theoretical and experimental value in 5th dial indicator are all little, its value is less than $1 \mathrm{~mm}$. That the displacement value is too little is main reason resulting in obvious difference between theory and experiment. 


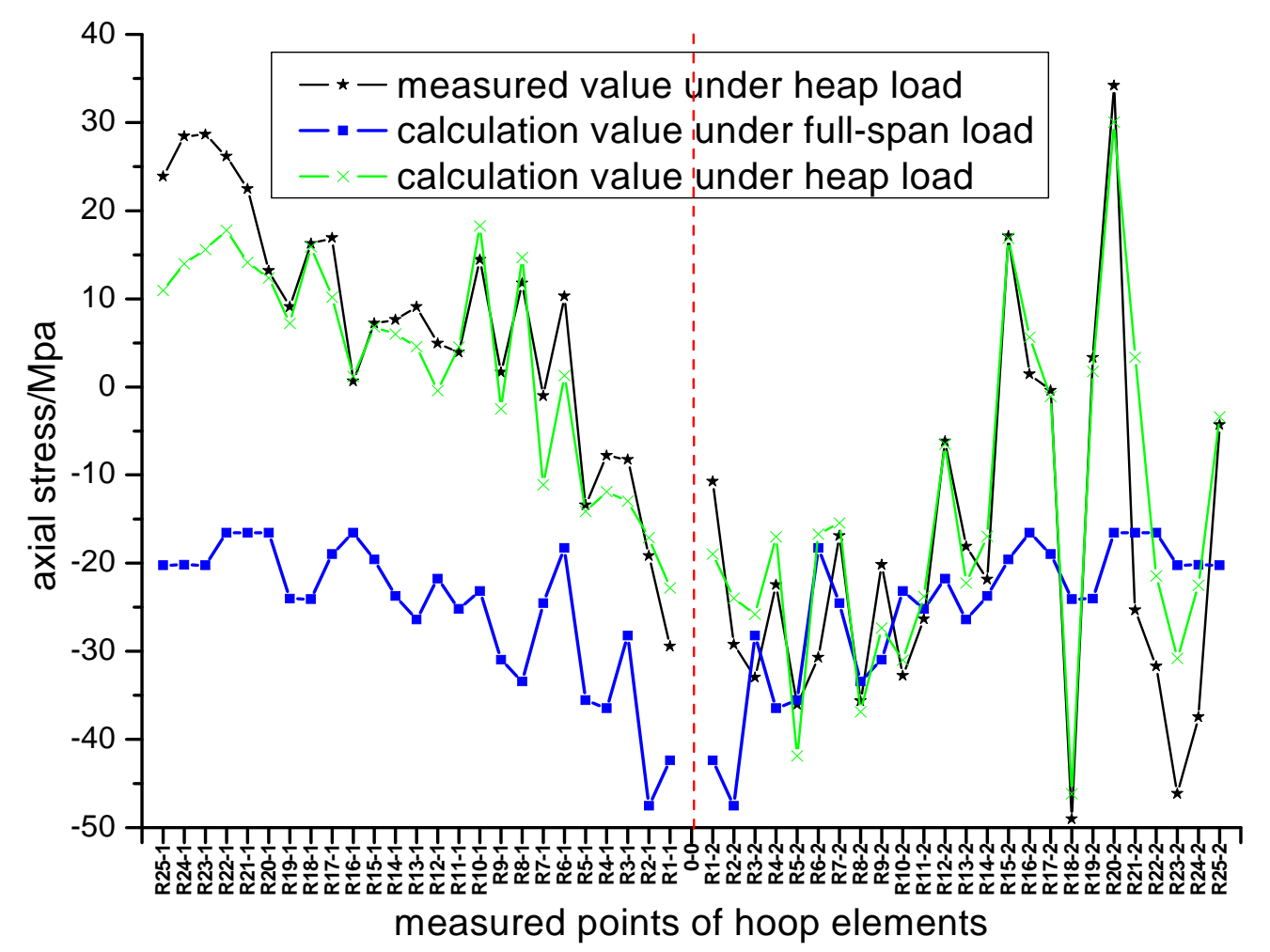

(a) Distribution of Radial Elements Stress after the Last Loading

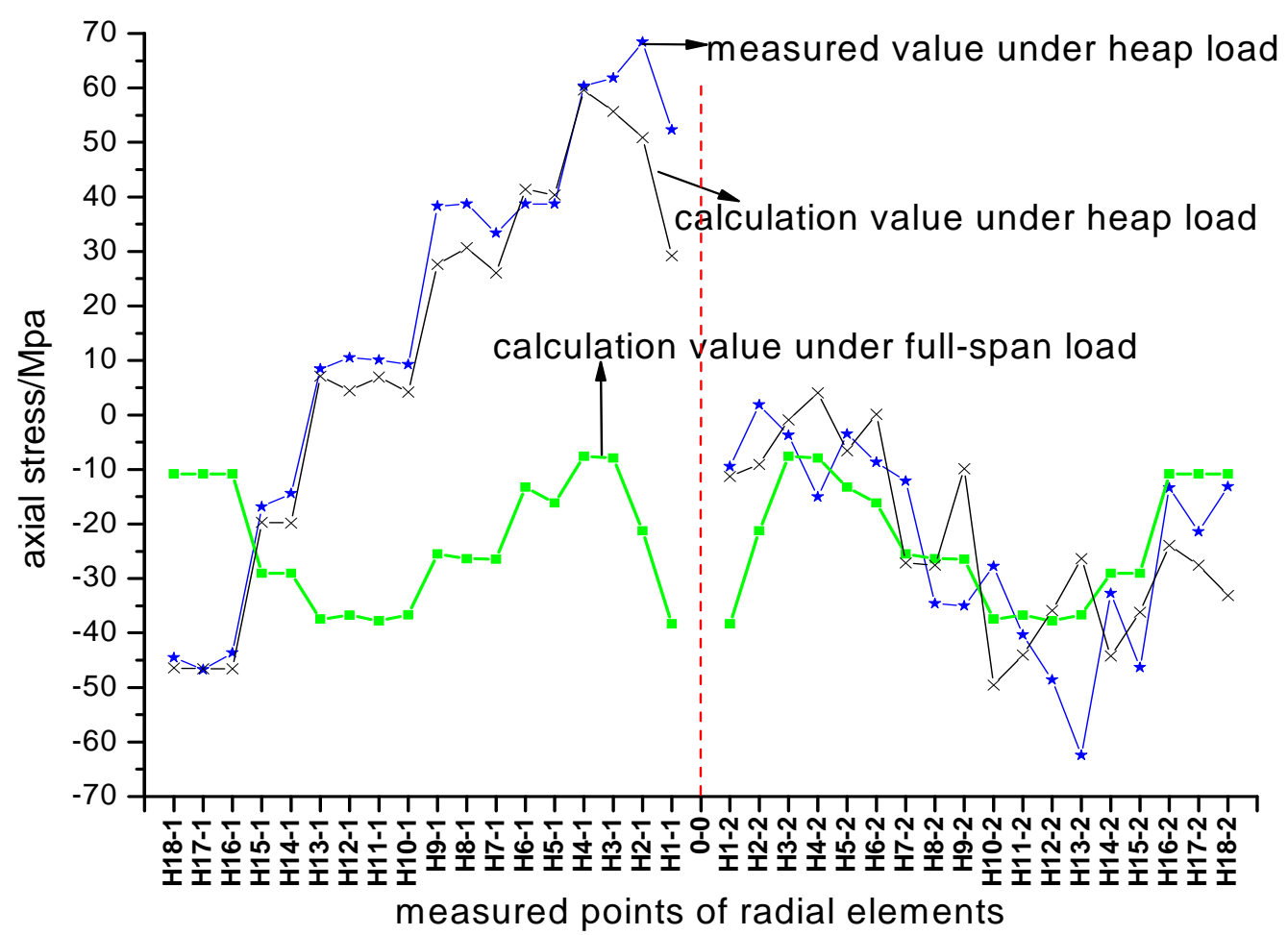

(b) Distribution of Hoop Elements Stress after the Last Loading 


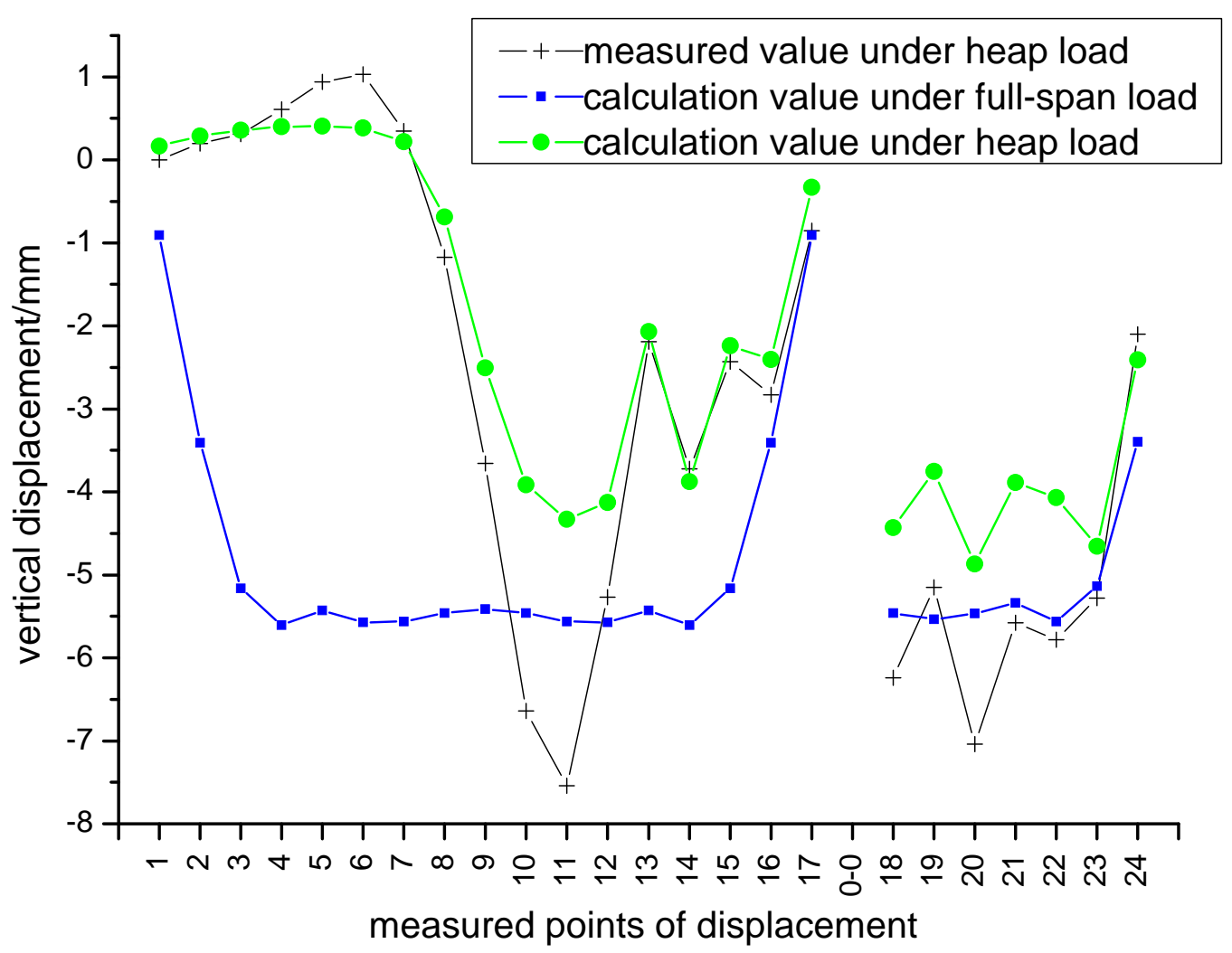

(c) Distribution of Nodal Displacement after Last Loading

Figure 15. Comparison of Distribution of Measured and Calculation Results

From Figure 15(a)-(b), we can see that the theoretical and experimental distribution under heap load are basically in well agreement. From Figure 15(a), we can see that the maximal and minimal stress of radial elements all appear in 2nd measured area, the maximal value is almost $40 \mathrm{Mpa}$, the minimal value is almost $-50 \mathrm{Mpa}$. The uniformity of stress distribution in 1st measured area is obviously better than 2nd measured area. At the same time, we can see that the distribution uniformity under heap load is obviously worse than full-span load, the maximal and minimal stress of radial elements all appear under heap load. Some radial elements are compressed, others are tensioned under heap load, but all radial elements are compressed under full-span load. From Figure 15(b), we can see that hoop elements in 2nd area are all compressed, while some elements are compressed others tensioned in 1st area under heap load. The maximal stress appears in 1st measured area, whose value is almost $70 \mathrm{Mpa}$. The minimal stress appears in 2nd measured area, whose value is almost $-65 \mathrm{Mpa}$. The stress distribution uniformity in 1 st area is obviously worse than in 2nd area. At the same time, from Figure 15(b), we can also see that the distribution uniformity under heap load is obviously worse than full-span load, the maximal and minimal stress of hoop elements all appear under heap load. Some hoop elements are compressed, others are tensioned under heap load, but all hoop elements are compressed under full-span load. From Figure 15(a)-(b), we can see that the maximal compress and tension all appear in hoop elements under heap load, whose values are less than sectional yield stress. 
From Figure 15(c), we can see that the maximal displacement under heap load increases $7 \mathrm{~mm}$ than the condition that the structural tension is completed but loading does not begin. Under heap load, nodes in $1^{\text {st }}$ area move downward greatly, In 2 nd area, nodal upward displacements are less. From Figure 15(c), we can also see that displacement uniformity in single-layer latticed shell under heap load is worse than full-span load. Some nodes move upward, others move downward under heap load, but all nodes move downward under full-span load.

Overall, the structural overall stability under heap load is little worse than full-span load. The stress distribution uniformity under heap load is obviously worse than full-span load, the maximal and minimal stress of elements all appear under heap load. Some elements are compressed, others are tensioned under heap load, but all elements are compressed under full-span load. The maximal compress and tension, whose values are less than sectional yield stress, all appear in hoop elements under heap load. Displacement uniformity in single-layer latticed shell under heap load is worse than full-span load. Some nodes move upward, others move downward under heap loads, but all nodes move downward under full-span loads.

\section{CONCLUSIONS AND SUGGESTIONS}

Based on the study, the results may be due to give some understanding on structural static property under heap load for suspen-dome and similar large span structure; conclusions and suggestions are as follows:

(1) The structural overall stability factor under full-span load is bigger than heap load.

(2) Theoretical and experimental data are basically in well agreement during experiment, it can be say that the design of experimental model, method and process of load, arrangement of measured points and process of measurement are satisfied with request .

(3) The stress distribution uniformity under heap load is obviously worse than full-span load, the maximal and minimal stress of elements all appear under heap load. Some elements are compressed, others are tensioned under heap load, but all elements are compressed under full-span load.

(4) The maximal compress and tension all appear in hoop elements under heap load, their values are less than sectional yield stress.

(5) Displacement distribution uniformity in single-layer latticed shell under heap load is worse than full-span load. Some nodes move upward, others move downward under heap load, but all nodes move downward under full-span load.

(6) Heap load is disadvantage to structural static properties, it is proposed that heap load should be considered during designing and some measures should be applied to avoid heap loads come into being during construction and active service.

\section{ACKNOWLEDGMENT}

These authors are highly grateful to the anonymous reviewers for their valuable suggestions. This work is supported by NSFC Grants (No. 51108259), Science \& Technology Program of Shanghai Maritime University (No.20120050), and Key disciplines Program of Shanghai Maritime University (No. 20100010). 


\section{REFERENCES}

[1] Dong, S.L., "The Development History, Innovation, Classification and Practical Application of Spatial Structures", Spatial Structures, 2009, Vol. 15, No. 3, pp. 22-43. ( in Chinese)

[2] Kawaguchi, M., Abe, M. and Tatemichi, I., "Design, Test, and Realization of "Suspend-Dome" System", Journal of IASS, 1999, Vol. 40, No. 131, pp. 179-192.

[3] Geiger, D.H., "The Design and Construction of Two Cable Domes for the Korean Olympics" $[\mathrm{C}] / /$ Proceedings of IASS-ASC E International Symposium on Shells, Membranes and Space Frames. Osaka : [s.n], 1986.

[4] Kitipornchai, S., Kang, W.J. and Lam, H.F., et al, "Factors Affecting the Design and Construction of Lamella Suspen-Dome Systems", Journal of Constructional Steel Research, 2005, Vol. 61, pp. 764-785.

[5] Gao, B.Q. and Weng, E.H., "Sensitivity Analyses of Cables to Suspen-Dome Structural System", Journal of Zhejiang University Science, 2004, Vol. 5, No. 9, pp. 1045-1052.

[6] Guo, J.M. and Dong, S.L., "Theoretical and Experimental Study on Tensioning of Suspend-Dome”, China Civil Engineering Journal, 2011, Vol. 44, No. 2, pp. 65-71. (in Chinese)

[7] Guo, J.M., Dong, S.L. and Yuan, X.F., "Morphological Analysis of Suspend-Dome Structures and Its Practical Analysis Method", China Civil Engineering Journal, 2009, Vol. 41, No. 12, pp. 1-7. (in Chinese)

[8] Chen, Z.H. and Qin, Y.L., et al, "An Experimental Study on Rigid Suspen-Dome Structures", China Civil Engineering Journal, 2006, Vol. 39, No. 9, pp. 47-53. (in Chinese)

[9] Zhang, A.L. and Liu, X.C., et al, "Static Experimental Study on the Model of the Suspen-Dome of the Badminton Gymnasium for 2008 Olympic Games", Journal of Building Structures, 2007, Vol. 28, No. 6, pp. 58-67. (in Chinese)

[10] Wang, Y.Q. and Guo, Z.X., et al, "Pre-stressed Cable Construction of Large-span Elliptic Suspen-dome in Changzhou Gymnasium”, Construction Technology, 2006, Vol. 37, No. 3, pp. 33-36. (in Chinese)

[11] Zhang, Z.H., Cao, Q.S. and Dong, S.L., et al, "Structural Design of a Practical Suspen-Dome”, Advanced Steel Construction, 2008, Vol. 4, No. 4, pp. 323-340.

[12] Chen, Z.H., Liu, H.B. and Wang,, X.D., et al, "Review and Forecast of Suspen-Dome Structures", Journal of Building Structures, 2010, Supplementary Issue 1, pp. 210-215. (in Chinese)

[13] Liu, F., Qian, J.H. and Song, T., et al, "Analysis of Reasons for the Collapse of a Hub Joint Steel Shell”, Spatial Structures, 2007, Vol. 13, No. 4, pp. 38-42. (in Chinese)

[14] Fu, H.Q, "Structure Experiment", Metallurgy Industry Press, Beijing, 1992. (in Chinese).

[15] JGJ 61-2003, "Technical Specification for Latticed Shells", China Architecture \& Building Press, Beijing, 2003. (in Chinese).

[16] ANSYS Users Manual Revision 6.1, ANSYS, INC., Inc,. Canonsburg, Pennsylvania, 2002. 